\title{
As chefias Tupinambá e suas ressonâncias entre sujeitos coletivos e individuais
}

Cinthia Creatini da Rocha1 Universidade Federal de Santa Catarina

Resumo: Este paper sintetiza algumas reflexões sobre os efeitos entre o fazer política, a constituição dos sujeitos individuais (caciques), coletivos ("cacicados") e a territorialidade Tupinambá efetivada, sobretudo, nas "retomadas de terras" e na consolidação de aldeias que se espalham no perímetro da Terra Indígena Olivença. Ademais, em meio ao panorama da política ameríndia, procura-se mapear o emaranhado de relações que definem e são definidas por uma multiplicidade de sujeitos que configuram redes e circuitos próprios.

Palavras-chave: Tupinambá; política ameríndia; movimento indígena.

${ }_{1}^{1}$ Doutora em Antropologia Social (UFSC, 2014). Mestre em Antropologia Social (UFSC 2005). Pós-doutorado no Programa de Pós-Graduação em Antropologia Social da UFSC, bolsista PNPD Capes (2017-2019). Realiza pesquisas junto a distintos grupos indígenas do Brasil desde 1998. Pesquisadora do Instituto Brasil Plural. 


\title{
The Tupinambá leaders and their resonances between collective and individual subjects
}

\begin{abstract}
This paper synthesizes some reflections on the effects of how political is doing, the constitution of individual subjects (caciques), collective ("cacicados") and Tupinambá territoriality, especially in "land repositions" (retomadas de terras) and in the consolidation of villages that spread in the Terra Indígena Olivença. Besides, in the midst of the panorama of Amerindian politics, we try to map the entanglement of relations that define and are defined by a multiplicity of subjects that configure networks and circuits of their own.
\end{abstract}

Keywords: Tupinambá; amerindian politics; indigenous movement.

\section{Las jefaturas Tupinambá y sus resonancias entre sujetos colectivos e individuales}

Resumen: Este documento sintetiza algunas reflexiones sobre los efectos entre el hacer política, la constitución de los sujetos individuales (caciques), colectivos ("cacicados") y la territorialidad Tupinambá efectuada, sobre todo, en las "retomadas de tierras" y en la consolidación de aldeas que se esparcen en el perímetro de la Tierra Indígena Olivenza. Además, en medio del panorama de la política amerindia, se busca mapear el enmarañado de relaciones que definen y son definidas por una multiplicidad de sujetos que configuran redes y circuitos propios.

Palabras clave: Tupinambá; política ameríndia; movimiento indígena. 
$\mathrm{E}$ ste artigo é parte das reflexões contidas em minha tese de doutoramento ${ }^{2}$, uma etnografia sobre o fazer política entre os Tupinambá de Olivença (Ilhéus, BA). Na ocasião, me ative a demonstrar que mesmo diante de um longo e intenso processo de colonização da região tradicionalmente habitada, expropriação territorial e invisibilidade étnica ${ }^{3}$, a partir do reconhecimento da identidade indígena no ano de 2001 pela FUNAI, os Tupinambá acionam um conjunto de princípios comparáveis àqueles observados entre outros coletivos ameríndios das terras baixas. Aqui, apresentarei em síntese, os efeitos entre o fazer política, a constituição dos sujeitos individuais (caciques), coletivos (cacicados) e a territorialidade Tupinambá, efetivada, sobretudo, nas "retomadas de terras" e na consolidação de aldeias que se espalham no perímetro da Terra Indígena. Ademais, navego neste panorama da política ameríndia mapeando o emaranhado de relações que definem e são definidas por uma multiplicidade de sujeitos que configuram redes e circuitos próprios. Como Michael Hardt comentou a respeito das contribuições de Deleuze e Guattari em Mil platôs (1997 [2012]): "o pensamento político e a ação política não podem prosseguir ao longo de uma linha reta".

O uso do etnônimo Tupinambá é um fenômeno tão recente na vida dos nativos de Olivença quanto o seu reconhecimento étnico pelo Estado-nação. Muito embora não seja novidade constatar que tanto neste como em outros casos, os denominadores étnicos nada mais são que expressões ou sinais do contato com o Estado - ou em tempos anteriores com a própria figura do colonizador - jamais se poderia desconsiderar a intencionalidade que é efetivamente posta em vigor pelos nativos ao fazerem uso destes etnônimos (Sztutman, 2012; Calávia Saèz, 2013). No caso dos atuais Tupinambá, se anteriormente ao seu reconhecimento étnico eram identificados como "os caboclos de Olivença" e faziam parte do cenário daqueles sujeitos que supostamente teriam deixado para trás suas raízes ameríndias para serem "assimilados" e, posteriormente, "invisibilizados" pelo Estado, foi após o ano de 2001 que passaram a assumir a identidade de um "Nós" (indígena) deflagrada para o exterior. Simultaneamente, observa-se que em suas dinâmicas étnicas e políticas internas o que interessa realmente não é diluir as diferenças, mas evidenciá-las a ponto de produzir figuras de eminência e coletividades distintas.

De acordo com dados da Secretaria Especial de Saúde Indígena (SESAI), em 2014 o povo Tupinambá de Olivença contabilizava 4.669 indivíduos, configurando a segunda maior etnia no estado da Bahia. Os Tupinambá estão distribuídos em diferentes "comunidades" ${ }^{4}$ dispostas em uma extensão aproximada de 47

\footnotetext{
2 "Bora vê quem pode mais": uma etnografia sobre o fazer política entre os Tupinambá de Olivença (Ilhéus, Bahia), PPGAS/UFSC, 2014.

3 A invisibilidade dos nativos de Olivença como indígenas deu-se em um processo histórico que também pode ser nomeado como "caboclização". Por um lado, este projeto de transformação identitária consolidou-se em termos políticos e jurídicos a partir da lei de terras de 1850, quando as Comissões de Demarcação de Terras Públicas passaram a definir se o aldeamento deveria ser extinto ou não, a partir do grau de "mistura" ou "mestiçagem" de sua população. Assim, no censo populacional de 1872 se destacava que os indígenas catequizados passavam a ser denominados "caboclos". Lima (1999) indica que na região amazônica o termo caboclo é empregado como categoria relacional que identifica aqueles que se encontram em uma posição social inferior em relação a do locutor ou locutora. Igualmente, este fenômeno ocorreu com os Tupinambá de Olivença que, até recentemente, eram comumente e, pejorativamente, conhecidos como "os caboclos de Olivença”.

4 Termo nativo que neste contexto pode ser traduzido como localidades, mas que, como bem lembra Alarcon (2013), não trata de uma divisão formal com limites claramente estabelecidos, já que as lógicas de integração das "comunidades" ao território são muito dinâmicas, sobretudo, no contexto de "retomadas". Durante os trabalhos para identificação e delimitação da Terra Indígena Tupinambá de Olivença, o território foi dividido em 16 "comunidades". No entanto, durante a pesquisa em campo registrou-se que a SESAI e os próprios Tupinambá levam em conta a divisão do território em 23 "comunidades".
} 
mil hectares e que compreende parte dos municípios de Ilhéus, Buerarema e Una, configurando a Terra Indígena Tupinambá de Olivença (TITO). Em termos jurídicos e administrativos, até o presente momento a TITO conta com a publicação do Relatório Circunstanciado para Identificação e Delimitação da Terra Indígena (DOU 2009), mas aguarda a continuidade do procedimento de regularização fundiária que tem se mostrado extremamente moroso por parte da justiça brasileira. Além dos núcleos de ocupação indígena instalados no interior da Terra Indígena Olivença, há também famílias tupinambá que vivem em bairros ${ }^{5}$ da periferia da cidade de Ilhéus e que mantém redes de articulações sociopolíticas, econômicas e de parentesco junto aos habitantes da área indígena. Ao longo deste século XXI, os Tupinambá de Olivença têm se mostrado como ávidos protagonistas nas ações de "retomadas de terras" que, como veremos adiante, estão vinculadas a um processo de organização espacial, social e política muito peculiar.

O confinamento espacial e a supressão do território indígena fazem parte de uma história triste narrada pelos anciães tupinambá. Estes são pessoas de idade avançada, a sua maioria mulheres, que conseguiram permanecer nestas terras de origem ainda que em contraposição à perseguição, expulsão e morte de muitos dos homens nativos (seus maridos, pais ou irmãos) ${ }^{6}$. Os anciães são também conhecidos como os "troncos" dos Tupinambá, pois nasceram e hoje vivem no interior desta área considerada tradicional. Além disso, tais pessoas de idade avançada possuem um conhecimento próprio sobre aquelas famílias de nativos que apresentam algum vínculo histórico e territorial com a região.

O “movimento" político dos Tupinambá (mencionado acima) diz respeito à organização política dos indígenas desde o período em que buscaram o reconhecimento étnico até os dias atuais. Ainda que foque a demarcação da terra indígena e o acesso às políticas públicas, o "movimento" não se define simplesmente como produto de uma temporalidade ou reivindicação dos Tupinambá. Mais que isso, ele é efeito e marco dessa ação política que os Tupinambá empregam não tão somente em direção ao exterior como, sobretudo, nas suas redes de relações internas que estabelecem as condições para quem será ou não envolvido no "movimento". Em outras palavras, o "movimento" é assim tomado sob o enfoque de um feixe de princípios que organiza as relações entre os Tupinambá, valendo-se da continuidade e da descontinuidade, da aproximação e do afastamento, das associações e rupturas que consolidam a multiplicação dos sujeitos coletivos e individuais. Mais do que compreender o "movimento" como um bloco homogêneo de organização política indígena, o interessante é observá-lo como fluxos incessantes das relações diferenciais que promovem o fazer e desfazer de grupos.

Dentre as ações mais importantes do "movimento" se colocam as "retomadas de terras" que foram usurpadas dos nativos de Olivença por ocasião do estabelecimento de não indígenas nesta região. As "retomadas" são ações encabeçadas por um cacique e pessoas de seu "cacicado"7 que ao identificarem uma área improdutiva ou abandonada no interior do território tradicional passam a erguer ali uma nova aldeia. As "retomadas" implicam assim em movimentos de expansão

${ }_{5}^{5}$ Os principais bairros da periferia de Ilhéus que abrigam famílias indígenas são Nossa Senhora da Vitória, Nelson Costa, Vilela e Couto.

${ }^{6}$ Durante a pesquisa observei que a maioria das mulheres anciãs que permaneceram no território de origem possibilitando que as futuras gerações também tivessem vínculos com a área - se casaram com homens "de fora", originários principalmente de outros estados da região nordeste.

7 O termo "cacicado" é uma noção nativa e refere-se ao conjunto de pessoas conectadas politicamente a cada cacique. Assim, cada cacique representa um "cacicado" que mobiliza uma ampla rede de relações sociopolíticas. Vale lembrar que na literatura antropológica, o conceito de "cacicado" adquiriu um sentido vago e ambíguo, "(...) uma alternativa para exprimir aquilo que está 'entre' ou 'a caminho' da sociedade com Estado, especificamente, entre o Estado andino e a 'anarquia' da floresta” (Sztutman, 2012: 298-299, grifos originais). Tal interpretação não faz qualquer sentido na compreensão do caso dos atuais Tupinambá. 
e legitimação dos caciques e seus "cacicados", posto que o objetivo de toda "retomada" é consolidar-se como uma aldeia de sucesso, economicamente autônoma e "forte na cultura".

Enquanto estive em trabalho de campo, nos anos 2011 e 2012, acompanhei o surgimento de alguns novos caciques entre os Tupinambá. Em pouco mais de dez anos, eles tinham passado de um cacique (aliás, a primeira cacique era mulher) para quatorze deles, mostrando-se ávidos por impor movimentos dinâmicos de constituição das figuras de chefia. Cada cacique reúne em torno de si as famílias que compõem seu "cacicado" e cada um costuma referir-se a este conjunto sociopolítico como o "seu povo". Se perante o Estado a noção de "povo" se constitui como um elemento importante para delimitar a imagem concisa de "um grupo étnico" que garanta aos Tupinambá objetivos concretos como a demarcação da terra indígena e o acesso às políticas públicas diferenciadas, internamente esta noção de "povo" esfacela-se ou pulveriza-se. Neste sentido, entendo que o fundamento da ação política está alhures: "não em uma forma rígida, mas sim em uma variação contínua de formas, que só cumpre ser compreendida quando se passa de um momento particular a outro, quando são analisadas diferentes soluções para diferentes eventos" (Sztutman, 2012:105).

\section{Grupo de Chefes}

Se há algo que se pode dizer sobre os chefes ameríndios é que são eles aqueles que começam algo. "Chefe é aquele que inicia um movimento, movimento este que simultaneamente constitui o grupo e o constitui como chefe" (Perrone-Moisés, 2011: 877). Enquanto alguns caciques tupinambá se vinculam unicamente ao coletivo do lugar onde vivem (seja uma aldeia ou uma "retomada"), outros, por sua vez, abrangem uma área geográfica maior que conta com a presença de diversas famílias, isto é, de múltiplas coletividades. Por exemplo, um cacique pode ter famílias que "orienta" 8 tanto na região costeira, quanto naquela das serras. $\mathrm{Ou}$, ao contrário, pode restringir seu "cacicado" apenas aquelas famílias que vivem na mesma localidade que ele. Assim, em uma mesma região geográfica onde se localizam coletivos autônomos que estabelecem ou não relações entre si, pode-se ter a atuação de um ou mais caciques, cada qual responsável por "suas famílias". O principal motivo que justifica a associação de um cacique com as famílias de determinada região deve-se ao fato dele argumentar que aquela área faz parte da trajetória histórica de sua família, isto é, de "seus antepassados" considerados "troncos" do lugar e que lá viveram.

Conforme pontuei acima, as "retomadas" se constituem como objeto privilegiado da ação política dos caciques tupinambá e a constituição de uma nova chefia tupinambá implica necessariamente em dispor de uma ou mais áreas onde as famílias indígenas que conformam o "cacicado" possam habitar. Neste sentido, as "retomadas" evidenciam um tipo de projeto sociopolítico que concilia pensamento, ação e relação entre pessoas. Ademais, elas parecem ocorrer como ondas sonoras que se disseminam, isto é, quando um cacique realiza uma nova "retomada”, certamente a notícia irá correr com rapidez e em pouco tempo, em algum outro lugar dentro desta terra indígena, outro cacique também estará se articulando para retomar uma nova área para seu "cacicado". Considero oportuno avaliar que diante a morosidade da justiça brasileira em garantir o reconhecimento da Terra Indígena Olivença, as ações de "retomadas", os modos próprios de 
existência nestes lugares e as relações sociopolíticas aí estabelecidas são justamente o que permite aos Tupinambá exercitarem o uso e ocupação tradicional na contemporaneidade.

Entre disputas e alianças, uma "retomada" sempre reforça a legitimidade e o poder de um chefe que, pode ou não ser apoiado por outros caciques. Os caciques se organizam em conjuntos que "estão aliados". Um determinado conjunto ora pode conter uns, ora outros. O jogo de alianças políticas é movente, alternante, pois são acordos por vezes pessoais que consolidam parcerias, e nestes casos as técnicas de persuasão são muito utilizadas. Pelo menos foi assim que uma liderança se manifestou em reunião para explicar como fazer para que um determinado cacique se aliasse a outro: "a política é feita no dia-a-dia, a gente vai conversando com ele para ver se ele muda".

Em meados de 2012, já afastada do trabalho de campo, recebi diversas notícias pela internet que provinham de diferentes interlocutores relatando o fato de que "os caciques estavam realizando uma série de retomadas para recuperar o território". Afirmavam ainda que, naquela ocasião, "os caciques estavam todos unidos". A assertiva me causava profundo estranhamento, pois ou eu tinha retornado com uma impressão completamente equivocada do campo, ou alguma coisa muito especial tinha acontecido para que os caciques tupinambá deixassem de lado suas divisões internas. Quase dois meses depois destas notícias voltei para mais um período de trabalho de campo e tive a certeza que minhas impressões iniciais não estavam equivocadas. Os caciques não estavam "todos unidos", mas aqueles envolvidos nas ações de "retomadas" tinham se articulado em duas frentes, dois conjuntos de aliados distintos que vinham "retomando" áreas muito próximas umas das outras.

Renato Sztutman distingue que há uma distância entre o plano da ação - o plano da liderança - para o plano da representação - o plano da chefia. Citando Detienne (2000) enfatiza que "representar, falar em nome de alguém, produzir uma aparência de homogeneidade, é diferente de reunir, de tomar conta, de começar, de fundar um lugar" (Detienne 2000 apud Sztutman, 2012: 18). Noto que os caciques tupinambá ainda que sejam explicitamente voltados para este plano da representação face o exterior, precisam dar conta da vida na aldeia. Isto é, precisam cotidianamente demonstrar dedicação e interesse por aquelas famílias que fazem parte do "cacicado".

Por sua vez, José Glébson Vieira indica que a composição da esfera da chefia é um "movimento que parte da ação para a representação, isto é, da predação (ação) à domesticação ou produção de uma interioridade (representação)" (2010: 27). Esta última interpretação me parece muito sugestiva para enquadrar o caso dos atuais Tupinambá, pois mesmo que os caciques nem sempre consigam estar no dia-a-dia ao lado das famílias que compõem o seu "cacicado" - e muitas vezes são cobrados por sua ausência -, eles não podem deixar de se mostrarem atentos e preocupados com estas famílias que lhes apoiam. Portanto, devem partilhar suas conquistas oriundas do exterior, sobretudo, aquelas materiais relacionadas a benefícios, projetos, recursos para a aldeia, etc.

Se em seus discursos públicos os Tupinambá evocam sempre a imagem de um "Nós”, internamente observa-se que as ações políticas visam o "Múltiplo", ou seja, os caciques precisam antes de tudo garantir as condições mínimas para que o "seu próprio povo" se mantenha. Isso se passa tanto no plano da escola ou dos atendimentos a saúde indígena, quanto no nível dos eventos e festas realizados na terra indígena. Aliás, o maior evento ritual e político que ocorre anualmente, a Caminhada em Memória dos Mártires do Rio Cururupe, é um dos momentos 
mais privilegiados para se observar como cada cacique se lança em uma corrida pessoal junto a seus aliados externos, objetivando angariar, sobretudo, os alimentos que serão preparados e distribuídos para o consumo coletivo na aldeia de cada um deles logo após o encerramento do evento.

Acompanhei os preparativos e o evento da Caminhada em 2011 e 2012. Os Tupinambá começaram a realizar este evento político-ritual em setembro do ano 2000 e de lá para cá o mantiveram anualmente como a principal atividade de encontro e reunião do "povo Tupinambá". Todo ano a Caminhada se estrutura de modo similar. No último domingo do mês de setembro, logo cedo pela manhã, após se encontrarem na praça de Olivença, os Tupinambá formam um grande círculo na frente da igreja Nossa Senhora da Escada e ali realizam uma oração em meio ao chacoalhar dos "maracás". Algumas músicas do repertório do Poranci ${ }^{9}$ também podem ser entoadas e em seguida todos entram na igreja. Seguem até o altar e recebem a benção do padre que está por concluir a missa das oito horas da manhã. Em fila, tendo os caciques à frente, os indígenas caminham até a ladeira que acessa a beira da praia e a rodovia Olivença-Ilhéus (BA-001). Uma multidão de pessoas desce a ladeira cantando músicas do Poranci e o grupo segue ao longo de quase sete quilômetros perfazendo um total de aproximadamente três horas de caminhada em ritmo intenso.

Mas, a imagem deste grande bloco humano que aparentemente parece coeso, internamente sustenta suas fissuras. Os caciques que "estão aliados" naquele ano caminham lado a lado e as pessoas de cada "cacicado" também procuram permanecer próximas. Os grupos fragmentados no interior deste grande grupo explicitam as rupturas e diferenças que apresentam entre si. Um modo de notar estas dissonâncias é através das músicas, pois por vezes as músicas entoadas por quem está no início ou no final desta multidão são diferentes, se sobrepõem ou se atravessam umas às outras. $\mathrm{O}$ ritmo das passadas de igual maneira explicita as diferenças, aqueles que estão na linha de frente do "cardume humano" imprimem um ritmo acelerado enquanto cantam e se deslocam. Já quem está mais ao final do grupo caminha com certa lentidão, dando visibilidade aos distanciamentos. A Caminhada espelha o que também se observa no cotidiano do fazer política dos Tupinambá, a constante dinâmica entre tendências centrípetas e tendências centrífugas (Perrone-Moisés, 2011; Sztutman, 2012).

Desde a primeira Caminhada é uma prática dos Tupinambá que seja servido um almoço coletivo para consagrar o evento. O fato de cada cacique levar "seu povo" para a "sua aldeia" deixa claro que a Caminhada é, sobretudo, um momento único para atualizar e reforçar as dinâmicas internas que dão conta da aproximação e do afastamento de sujeitos individuais e coletivos. Sendo a data da Caminhada um dia de muita festividade é importante que cada cacique demonstre certo investimento perante os seus. Assim, cabe aos caciques promoverem uma bela refeição para "agradarem" cada qual o "seu povo", e desta forma, reforçarem seus laços de apoio mútuo e legitimação. Semanas antes do evento, os caciques articulam suas redes de aliados externos para o provimento de gêneros alimentícios, bebidas, música (ao vivo ou mecânica), enfim, tudo que possa proporcionar uma grande comemoração entre as famílias presentes. Não à toa, no dia posterior ao evento, o assunto mais comentado em todas as rodas de conversa, seja na aldeia que for, trata daquilo que cada cacique ofereceu aos seus. As avaliações

9 Conhecido entre outros povos indígenas do Nordeste como Toré, o Poranci reúne em suma dança, cantos, rezas e a sonoridade dos maracás. Sem jamais ter ouvido qualquer justificativa para esta distinção, acredito que utilizar o termo Poranci é mais uma forma dos Tupinambá marcarem suas diferenças em relação aos demais povos indígenas desta província geográfica. 
apontam desde a refeição mais farta e saborosa, até o número de visitantes que cada aldeia recebeu.

A Caminhada acaba por ser um dos principais eventos políticos dos Tupinambá não somente porque marca a resistência histórica e a visibilidade frente ao exterior, mas principalmente, porque sintetiza os princípios de lealdade, solidariedade, cumplicidade e atenção que estão dispersos nas relações cotidianas do fazer política entre cacique e seus grupos. Os caciques que não se destacam pelo almoço servido em um determinado ano tendem a ser vistos como aqueles que apresentam redes de relações externas mais frágeis ou fragilizadas. Fato que pode deixar as pessoas destes "cacicados" atentas, pois a contração das relações de um cacique se reflete no próprio grupo. Na esteira de Strathern $(1988,1991)$, "há de se compreender que a gênese destas pessoas não pode ser dissociada da gênese de coletivos, pois assim como as pessoas, os coletivos - que lhe são homólogos submetem-se a movimentos de contração e extensão" (apud Sztutman, 2012: 11).

Em algumas reuniões de caciques e lideranças que acompanhei ou mesmo de algum cacique com apenas os membros de seu cacicado, a pergunta que sempre surgia era: “afinal, quantos caciques se têm entre os Tupinambá?” Nestes momentos, a impressão que eu ficava era de que o número exato de caciques jamais fosse possível de mensurar, pois a probabilidade de surgir um novo a qualquer momento estava sempre posta como uma realidade da política local. Indagados em diversas ocasiões sobre realmente quantos eram, às vezes nem mesmo os caciques sabiam responder com precisão a pergunta. $O$ surgimento de um novo cacique é sempre um horizonte possível e certamente desejável por alguém. Ainda que não seja uma tarefa fácil, afinal os caciques também estão na mira dos não indígenas que os perseguem para minar suas reivindicações, deve-se reconhecer que internamente ocupar tal posição é motivo de admiração e prestígio. Afinal, como pessoas que estão no ápice deste conjunto de eminentes, os caciques têm bem mais acesso a informações, bens materiais, realizam viagens, participam de cursos, reuniões, seminários, ampliam a rede de pessoas conhecidas, são procurados como interlocutores potenciais de pesquisadores e outros não indígenas, além de decidirem em muitos casos, sobre a vida das próprias pessoas ligadas ao "cacicado", ou seja, resolvendo as pendências e rupturas internas e decidindo quem fica e quem sai da aldeia.

A fala de uma mulher liderança quando indagada sobre como surgem os caciques e demais lideranças coloca questões interessantes para a reflexão:

\begin{abstract}
Os lideranças do passado já eram formados pelos mais velhos. Porque quando a gente tem os nossos filhos, vai vendo a diferença de um pro outro. Então dali a gente vai descobrindo o dom daquele que a gente vê que tem o dom. Cada um tem um dom marcado por Deus. Então se a gente via que um tinha o dom, nossos mais velhos já tinham o cuidado de estar cuidando daquela criança. E mais tarde esta iria ser uma liderança que ia ser um grande fruto no nosso território. Então, quando se fazia uma liderança, era justamente os mais velhos que formavam, na base de todo o cuidado. Tinham as suas ciências de rezas, seus banhos com as suas raízes, tinha o dia certo pra pegar aquele jovem, botar sentado num banco e rezar, e ensinar umas orações boas. [...] Hoje ta nascendo liderança, não tão mais se fazendo. [...] Hoje a gente tá indo pra um tanto de caciques, mas quem são esses que não se reúnem com os mais velhos? Quando em 2001, Jamopoty foi escolhida, antes a gente fez um ritual bem forte com ela, um Poranci. Os mais velhos disseram que ela ia ter barreiras, mas ela tinha também o voto de confiança da comunidade. Enquanto isso, outros hoje estão sendo por conta deles, porque querem ser, mas muitas das vezes a gente tem vontade, mas nunca podemos ser aquilo que se quer e só o que Tupã permite.
\end{abstract}

Há uma evidente crítica sobre a necessidade dos atuais caciques tupinambá serem mais bem preparados em termos "espirituais", com o suporte e acompanhamento dos anciãos que lhes devem preparar o corpo e o espírito para que 
sejam "fortes" e aguentem os desafios desta posição. Fui informada consensualmente que um cacique escolhido jamais seria deposto, a não ser que, por decisão pessoal, optasse por deixar esta função. Ainda assim, me parece que a intensa busca destes personagens por legitimidade e diferenciação indica que a posição de cacique não é um porto seguro. Um cacique será sempre cacique enquanto tiver um grupo de pessoas aliadas, mesmo que sejam apenas membros de sua família extensa. Porém, entre ser cacique de um pequeno ou de um grande grupo há certamente uma boa diferença. Na verdade, os caciques precisam de um grande número de parentes para sustentá-los, ou pelo menos, é o que costumam dizer quando cada um deles afirma que sua família "é muito numerosa".

Entre os Potiguara, Vieira observou que a disputa por cargos de liderança leva ao aumento do número de cadastramentos de indígenas, algo que denominou de "política do cadastramento", motivada pela necessidade de cada candidato conquistar novos votos, tendo em vista que a escolha de um cacique passa por um processo de votação (2010:139). Já entre os Tupinambá não há qualquer espécie de votação para consagrar caciques ou lideranças, contudo, de igual modo, é necessário que cada cacique se mostre capaz de mobilizar o maior número possível de famílias e criar alianças políticas que lhes dê apoio e legitimidade.

Ao mesmo tempo em que os caciques se lançam para o exterior em busca de prerrogativas para si e os seus, um cacique que passa mais tempo "fora da aldeia" pode passar a ser visto com certa restrição pelas famílias atreladas a ele. Ou mais, um cacique que não mantém uma certa prática de visitas e conversas com as famílias de seu "cacicado" também está sujeito a uma provável instabilidade política. É aqui que entra um dos temas mais clássicos da obra de Pierre Clastres: a oratória do chefe ameríndio. Como bem coloca este autor no artigo O dever da palavra, "toda tomada de poder é também uma aquisição de palavra" ([1974] 2003: 169). Aliás, a oratória seria uma das características mais importantes das chefias indígenas. Os Tupinambá salientam que um dos principais atributos de um cacique se refere ao conhecimento da leitura e da escrita, ainda que muitas vezes a produção de documentos seja feita pelos professores e lideranças que os apoiam. Mas, incontestavelmente, o "dom da palavra" é o que transparece como uma das principais qualidades destes sujeitos proeminentes. Assim me disse um cacique:

A questão do ser cacique é cultural, o povo tupinambá te reconhece pelo trabalho que tu vem fazendo dentro da aldeia. Tem que estar o tempo todo tendo palavras que não gerem conflitos, mas que resolvam. Eu tenho relação com todas as comunidades, em cada uma pelo menos tenho um grupo de famílias que passa pela minha orientação. Existem aquelas principais, com que tenho uma orientação maior.

Esta prática de manter-se próximo dos seus, gerando palavras “de paz” foi brilhantemente sintetizada por Clastres:

\footnotetext{
Se nas sociedades com Estado a palavra é o direito de poder, nas sociedades sem Estado ela é, diversamente, o dever do poder. As sociedades indígenas não reconhecem ao chefe o direito à palavra porque ele é chefe: elas exigem do homem destinado a ser chefe que ele prove seu domínio sobre as palavras. Falar é para o chefe uma obrigação imperativa, a tribo quer ouvi-lo: um chefe silencioso não é mais um chefe. (Clastres, [1974] 2003: 170-171, grifos originais)
}

Quando uma das caciques comentou comigo que vinha sentindo-se "esquisita", o principal fato que lhe intrigava era o "silenciamento de sua voz", principalmente durante reuniões importantes com a presença de outros caciques e lideranças. Ela me dizia que não sabia o que vinha acontecendo, mas sentia que 
não conseguia falar, como se algo lhe trancasse a voz. Soube dias após a nossa conversa que ela teria ido procurar um pajé para resolver o problema e este lhe levou à mata para "buscar a força dos espíritos".

De acordo com Vieira, o uso da palavra pelo chefe - no sentido de aconselhar - se relaciona a um dever que é acionado em nome do coletivo. "Ela sugere a habilidade em estabelecer diálogo e mediações, mas também significa o próprio exercício da chefia em termos de convencimento e da extrapolação do nível mínimo de socialidade dos indígenas" (2010: 154). Aliás, "convencimento" é uma habilidade que não pode faltar nas ações políticas dos caciques e das lideranças indígenas. Ao se reunir com as famílias coletivamente ou visitá-las uma a uma, o cacique deve constantemente justificar suas viagens, suas participações em seminários, alegando sempre que seu trabalho refere-se à "luta e à defesa do povo".Os caciques precisam justificar sua existência diante o grupo e, mais que isso, sua própria ausência em muitos momentos do dia-a-dia. As palavras dos caciques se colocam para enfatizar que "o povo é prioridade" e que estão sempre focados em novas conquistas para serem revertidas às famílias indígenas. Como bem expõe Sztutman sobre o chefe, este: "[...] deve se fazer plenamente visível, ele deve exteriorizar suas relações (e sua magnitude) para ser plenamente controlado" (2012: 311).

\section{Chefe de grupos}

Pierre Grenand observou que os Wajãpi "questionam o excesso de poder, mas admiram a força” (1982: 236 apud Sztutman, 2012: 321). Os caciques tupinambá são admirados pelos "cidadãos comuns" (os não eminentes), contudo o excesso de poder lhes é algo completamente abominável, especialmente se tal excesso se mostrar sob a forma de um "poder de mando". Em vários momentos em que os indígenas se afastaram de um cacique ou liderança, a justificativa acionada explicitava o desacordo com a possibilidade de sentirem-se "mandados". Clastres já havia destacado que entre chefe e grupo se estabelece um jogo sutil, que:

\footnotetext{
consiste para o primeiro em saber a todo instante apreciar e avaliar as intenções do segundo, para fazer-se em seguida seu porta-voz. Tarefa delicada, feita de sutilezas, essa de realizar-se sob o discreto, mas vigilante controle do grupo. $\mathrm{O}$ menor abuso de poder (isto é, o uso de poder) identificado pelo grupo, e acabou-se o prestígio do chefe: ele é abandonado em proveito de outro mais consciente de seus deveres. ([1980] 2011: 62)
}

Esta cautela em relação a uma postura de mando ou concentração de poder da parte dos caciques tupinambá também se destina no horizonte das demais lideranças indígenas. Nas eleições para vereador em 2012, um dos candidatos indígenas montara uma estrutura com carro de som na praia do Cururupe, local onde as pessoas se reuniriam após o trajeto da Caminhada vinda desde Olivença. Anualmente, é nesta praia que o percurso da Caminhada se encerra com o ápice das falas dos anciãos, dos caciques e demais lideranças indígenas. Acontece ali um dos momentos mais importantes do exercício da oratória para as pessoas de destaque, quando elas reforçam e legitimam sua posição perante os demais lhes apresentando um discurso coerente com os anseios dos indígenas. Fala-se sobre a historicidade dos Tupinambá, sobre a "luta" e o "movimento", marca-se questões identitárias e entoa-se cantos para que os Encantados se manifestem.

Porém, neste ano de 2012, a ordem e o tempo dedicado às falas dos nativos não seguiu o script de sempre. Assim que os caminhantes chegaram à praia, o 
candidato a vereador conduziu a ordem das falas dando prioridade para si e contrariando a etiqueta indígena. O público mostrou-se explicitamente desmotivado com o discurso político "vazio" e autopromocional que não lhe dizia respeito. Enquanto a voz do candidato ecoava nas caixas de som, algumas famílias iam se afastando da área central e se acomodando nos bares ou na areia da praia. Aqueles que insistiam em permanecer no círculo aguardando os discursos dos anciãos e dos caciques percebiam o quanto estes estavam atônitos e aborrecidos com a situação.

Posteriormente, vim a saber, que o referido candidato indígena não tinha conseguido o número de votos necessários para consolidar sua eleição. Diante disso, muitas pessoas comentaram comigo que isto ocorrera porque ele havia "contrariado o povo no dia da Caminhada". Como sintetizou uma anciã: "o índio sabe o que fazer, não precisa ninguém pra mandar nele". Em outras palavras, as pessoas que estavam presentes naquela ocasião rejeitaram abertamente a atitude do candidato indígena e em represália deixaram de votar nele como vereador. Sua postura foi completamente rechaçada, pois ele sobrepôs seus interesses pessoais diante os interesses da maioria que estava presente aguardando a oratória dos eminentes.

O exercício do poder de alguém que apresente certa autoridade não deve ser dirigido aos Tupinambá por intermédio de uma relação que sugira a subordinação, mas sim que indique a "influência" ou em seus próprios termos, a "orientação". Como me disse uma mulher anciã irmã de um cacique: "índio tem chefe, o que não tem é patrão!" O que está em questão nesta relação entre indígenas eminentes e outros não eminentes parece passar longe de uma ideia de obediência ou sujeição.

Assim como frequentemente eu ouvia dos chefes tupinambá que "não há cacique sem comunidade", a comunidade também precisa da "orientação" de um cacique para acessar as prerrogativas do exterior. E uma via de mão dupla. Se no princípio do "movimento" a figura de "um cacique" foi fundamental para consolidar uma unidade étnica perante o Estado-nação, hoje o que transparece é que são os caciques que precisam muito mais de suas comunidades para se legitimarem como tais. Já que a qualquer momento alguém pode irromper do grupo, é preciso que o cacique se mostre como alguém de confiança, ao mesmo tempo em que confia nos seus - até que lhes provem o contrário. Os efeitos da vigília e do controle, portanto, são muito mais direcionados para um cacique do que para os membros de um "cacicado". A admiração perante os caciques não significa a crença nos mesmos, a inconstância a qual os ameríndios estão sujeitos os leva a cindir para outros lados caso isso se faça necessário.

Mas a análise desta relação não se encerra por aqui. Ao mesmo tempo em que os caciques devem se mostrar afetos aos seus, "capturando" prerrogativas no exterior para partilhá-las com os "parentes", muitas vezes as pessoas atreladas a determinado cacique também se sentem responsáveis por lhe retribuir de alguma forma o trabalho que ele vem realizando. Por ser uma posição não remunerada, alguns caciques chegam a "esperar" que as famílias espontaneamente lhes ofereçam produtos oriundos de seu próprio trabalho como se fosse um tipo de compensação. Nestes casos, o mais comum é que as famílias levem para o cacique farinha de mandioca, frutas, verduras ou mesmo qualquer outro alimento que se possa ter em casa. É como se as famílias - sobretudo aquelas bem próximas precisassem se mostrar generosas para com o "seu cacique", retribuindo de alguma forma o trabalho que este realiza em função dos interesses coletivos que lhe 
impedem de possuir algum trabalho fixo ou mesmo uma área de roça permanente.

Certa vez, soube de uma situação em que um morador mandou uma quantia pequena de farinha para o cacique e este se mostrou bastante chateado, alegando que sabiam que ele não tinha condições de produzir para sua própria família. Sentindo-se inclusive afrontado, o cacique chegou a pensar em devolver o produto, mas acabou deixando por isso memso. Dias depois, veio me contar que tinha recebido mais farinha do dito morador, provavelmente porque estereconhecra o quanto teria se mostrado sovina. Coloco em cheque se o doador da farinha realmente quis redimir-se espontaneamente, ou se chegou até ele os boatos sobre o incômodo do cacique que colocavam em cheque a sua generosidade.

Nas aldeias, a moradia do cacique acaba sendo sempre aquela que congrega o encontro de mais pessoas. Em geral, chega-se ali para buscar "orientação" sobre alguma demanda pessoal ou problemas que possam estar envolvendo mais de uma família da aldeia. A cooperação econômica também é uma via que se institui junto ao cacique, sendo ele o principal responsável por partilhar alguns recursos oriundos da rede de aliados externos (a distribuição semanal de leites, cestas básicas, sementes, ferramentas, etc.). Em sua casa, portanto, convergem pessoas, bens (materiais e simbólicos) e se irradia relações.

Vimos acima que no que se refere aos eventos festivos como a Caminhada, que agrupam as famílias pertencentes a cada "cacicado", os preparativos a serem realizados na aldeia do cacique contam especialmente com a participação das famílias das lideranças locais. Nestes momentos, ainda que o envolvimento de muita gente seja visível, os créditos posteriores são dedicados ao cacique, visto ter sido ele/ela o principal responsável por “capturar” os bens materiais necessários para a realização do evento em sua aldeia. Também quando se trata daquelas atividades de caráter coletivo, como o são os mutirões de limpeza, a construção de um novo núcleo escolar ou espaço para reuniões, cabe destacar que são geralmente as famílias mais próximas ao cacique, ou seja, aquelas de suas lideranças, que estão diretamente envolvidas. E nos casos em que não são pessoas ligadas a alguma liderança já instituída, pode-se ter certeza que os envolvidos estão pleiteando tal aproximação política com o cacique local, mostrando-se aptos a colaborarem em todas as demandas necessárias para a consolidação das boas relações.

Isto gera, obviamente, uma separação entre aquelas famílias que se envolvem nas atividades da aldeia e as outras que permanecem de certo modo afastadas das mesmas - há assim aqueles que participam da vida local e aqueles que apenas vivem no local. Tal separação transcende distintos níveis, pois se algumas famílias podem vir a questionar o fato de um cacique muitas vezes privilegiar (com bens e serviços) aqueles que lhe são mais próximos, por outro lado, elas também não se sentem ou não se esforçam para tornarem-se "mais próximas" do mesmo.

Os indígenas bem sabem que é através da articulação com os agentes externos que conseguem se "fortalecer" em termos materiais e simbólicos. No período anterior ao "movimento", a presença da Pastoral da Criança representada por uma mulher nativa que trabalhava com a entidade distribuindo leite, roupas, objetos para crianças pequenas e alimentos, lhe trouxe um capital simbólico que, posteriormente, foi importante para sustentar a filha que veio a se tornar uma cacique.

Nesta mesma linha, observei durante o período da realização do trabalho de campo que existia uma ong que atuava com projetos e recursos audiovisuais e que se colocava como uma das principais vias de acesso a recursos tanto financeiros 
(para aqueles indígenas que trabalhavam em sua estrutura), quanto materiais (especificamente equipamentos como computador, internet e a rádio comunitária). Além disso, esta organização realizava cursos de formação para os indígenas possibilitando a aquisição de capital simbólico. Presenciei alguns momentos em que caciques e lideranças acusavam a entidade de beneficiar somente as pessoas ligadas a um cacique. Eram situações sempre constrangedoras em que os profissionais desta organização tentavam se redimir e reverter a imagem negativa junto aos indígenas mais críticos. De fato, a reclamação fazia sentido, quem mais se aproximava da entidade eram mesmo pessoas ligadas a um único cacique. É uma situação similar àquela das famílias das lideranças de um cacique que estão sempre mais próximas deste, ajudando, se envolvendo e recebendo as benesses como retorno.

Cada aldeia possui um determinado conjunto de condutas moralmente esperadas por parte dos moradores. Não são regras explícitas, mas que fazem parte de uma moralidade partilhada para a boa convivência. Quando ocorre algum problema que envolva pessoas de uma mesma família ou de mais de uma família do lugar, então uma liderança ou o vice-cacique deve vir a colocar o cacique responsável a par do assunto. Os caciques devem necessariamente se posicionar sobre o problema e acabam até mesmo decidindo quanto aos desdobramentos de uma pendência familiar, como em casos de infidelidade conjugal ou de violência doméstica, por exemplo. É interessante observar que se as pessoas envolvidas na questão não forem muito achegadas ao cacique, o assunto poderá ser tratado sob a mediação da figura de uma liderança local.

Em geral, ao acompanhar alguns caciques em suas interações com pessoas de seu "cacicado", em caminhadas nas casas das famílias ou em reuniões, por exemplo, sempre notei que havia um certo esforço da parte destes chefes por mostrarem-se simpáticos e atenciosos com as pessoas que lhe prestavam apoio político. Inclusive, se fosse o caso de chamar atenção por alguma atitude inadequada, mas que pudesse gerar algum constrangimento, o comentário do cacique era feito em tom de brincadeira ou deboche. Foi assim que uma cacique dirigiu-se a um índio que estava retornando à aldeia depois de um longo período vivendo na cidade. Enquanto ele estivera afastado, sua casa na terra indígena tinha permanecido fechada e assim lhe disse a cacique ao vê-lo retornar: "Olha, até que enfim, eu estava prestes a mandar derrubar sua casa. Hora dessas você vai chegar e ela vai estar no chão". O homem deu um sorriso sem graça e pouco tempo depois apareceu na casa da cacique para lhe presentear com algumas frutas.

Este exercício da "boa convivência" marca a postura dos caciques que sabem bem que não podem "dispensar" as famílias que lhes apoiam, mas também devem explicitar algumas regras para o convívio social e demonstrarem sua autoridade. Em certas situações é preciso inclusive apresentar uma atitude solícita para dar conta das múltiplas demandas que vão sendo apresentadas pelas famílias indígenas, especialmente quando o cacique resolve visitá-las em suas casas ou quando se reúnem para uma conversa com o mesmo. Em uma das andanças de um cacique que acompanhei visitando as famílias de uma de suas áreas de influência, reparei que em cada casa que ele visitava, acabava comentando um assunto ou atendendo uma demanda como forma de reafirmar suas alianças políticas com os moradores locais. Assim, ora eram sementes que prometia entregar a família, ora a agilidade em levantar determinada documentação para a contratação de alguém como servidor, ou aposentadoria, ou ainda outros benefícios de saúde, bolsa escola e cesta básica. 
Neste panorama, os caciques se destacam por possuírem conhecimentos, acessos e experiências que lhes diferenciam dos demais. A leitura e a escrita já são de saída signos importantes desta diferenciação, principalmente diante àquelas pessoas que ainda são quase analfabetas. Além disso, os trânsitos para o exterior, especialmente em viagens, garante aos caciques a aquisição de conhecimentos heterogêneos. Neste sentido, ao retornarem para a terra indígena reafirmam sua legitimidade compartilhando os desdobramentos das viagens, dos seminários e reuniões que participaram.

Os caciques são vistos como pessoas fortes, pois contém em si muitas relações, além daquelas externas, também junto aos familiares que mantém sob sua proteção e controle, assegurando-lhes bem-estar. O prestígio de um cacique é resultado da captação e redistribuição de bens e recursos, da aquisição de conhecimentos e prerrogativas do exterior, da rede de pessoas que lhe apoia, bem como do dom da oratória que deve mostrar-se tanto entre os indígenas, quanto diante os não indígenas. A ação política do líder, portanto, consiste na demonstração em partilhar suas habilidades e as experiências vivenciadas para além da terra indígena, sendo que seu grande desafio é dar conta das demandas de toda a comunidade - isto é, de todas as famílias que configuram o seu "cacicado".

\section{Considerações finais}

Vimos ao longo destas linhas que a Caminhada em Memória dos Mártires do Rio Cururupe se constitui como o principal ritual dos Tupinambá, posto que concilia aspectos da política, da sociologia e da cosmologia dos indígenas. Mesmo diante um longo período em que as famílias nativas viveram sob condições de subserviência e atrelamento aos proprietários rurais que se instalaram na região e usurparam suas terras, desde o reconhecimento étnico pelo Estado, os indígenas vêm agenciando formas próprias de se organizarem territorialmente, culturalmente e politicamente. Tais modos de se colocarem no tempo-espaço indicam que há sim muitas possibilidades de se estabelecer diálogos e encontros entre os dados etnográficos registrados entre populações indígenas do Nordeste - que deixaram de ser consideradas como tais diante um intenso processo de invisibilização das mesmas - e outros povos das terras baixas que jamais perderam o estatuto de ameríndios.

Os meandros da composição dos sujeitos individuais estão necessariamente atrelados aos sujeitos coletivos, o que nos leva a constatar que o inchaço ou retração de um cacique reflete em dinâmicas semelhantes para o seu "cacicado". Os eminentes, como seres que potencialmente agem sobre o mundo, não são necessariamente "representantes" (em nossos termos) de um povo indígena que se volta para o Estado, mas de algum modo acabam por se tornar também uma espécie de Estado para o "seu próprio povo". Considerando que os Tupinambá apresentam a todo instante meios de controle de uma figura que possa se dizer unificadora - dadas as recorrentes multiplicações de sujeitos individuais e coletivos , isto não impede que de alguma forma, eles também contenham ou adquiram em si mesmos os vetores de uma certa "máquina estatal" (Deleuze \& Guattari, 1995[1980]; Sztutman, 2012). Ao mesmo tempo em que um cacique confere "aparência" a seu "cacicado", apenas o faz porque distribui entre os seus as conquistas (bens materiais e simbólicos) angariadas no exterior a partir de suas relações. Isto coloca aos caciques esta possibilidade de fazer às vezes de um certo Estado, ainda que, e felizmente, de modo completamente diverso ao nosso. O caso dos 
Tupinambá, na trilha de outras paisagens ameríndias, me leva a crer que as formas enrijecidas do Estado possivelmente não serão levadas a cabo, pois antes disso, os indígenas acionam seus próprios mecanismos de contenção do poder.

Rejeitando explicitamente o poder de mando, o que um chefe indígena necessita é ter "influência" sobre as pessoas de seu grupo, indicando sua capacidade de "orientação" àqueles que lhe são aliados politicamente. Assim, os caciques tupinambá são sempre pessoas que estão sob o crivo de uma certa vigilância. A postura, a oratória, as relações sociais, os encaminhamentos e resoluções de conflitos (internos ou não), as partilhas, a manutenção e valorização dos laços de parentesco, a presença constante e acompanhamento das atividades e circunstâncias da vida aldeã, a capacidade de proporcionar bens, serviços e festas para as famílias são algumas das atribuições esperadas de um cacique. Ao mesmo tempo em que se lança ao exterior, o chefe ameríndio deve continuamente manter seus vínculos e prestar contas às pessoas que estão no lugar de sua origem, nas aldeias. É neste pêndulo que se movimentam os caciques tupinambá, posição plena de instabilidade e variabilidade, que justifica a constante possibilidade de nos depararmos com o surgimento de um novo líder e, consequentemente, de um novo grupo.

Recebido em 30 de setembro de 2018.

Aprovado em 6 de maio de 2019. 


\section{Referências}

ALARCON, Daniela Fernandes. O Retorno da Terra. Dissertação de Mestrado em Ciências Sociais, Programa de Pós-Graduação em Estudos Comparados sobre as Américas, UNB, 2013.

CALÁVIA SAÈZ, Oscar. Nomes, Pronomes e Categorias: repensando os "subgrupos" numa etnologia pós-social. Antropologia em Primeira Mão, PPGAS/UFSC, Florianópolis, 2013.

CARVALHO, Maria Rosário \& CARVALHO, Ana Magda (orgs). Índios e Caboclos - a história recontada. Salvador, EDUFBA, 2012.

CLASTRES, Pierre. A sociedade contra o Estado - pesquisas de antropologia política. São Paulo: Cosac Naify, 2003 [1974].

. Arqueologia da Violência - pesquisas de antropologia política.

São Paulo: Cosac Naify, 2011 [1980].

DELEUZE, Félix \& GUATTARI, Gilles. Mil Platôs: capitalismo e esquizofrenia 2, vol.1. Trad. São Paulo: Ed.34, 1995[1980].

GODELIER, M. \& STRATHERN, M (orgs.). Big Men and Great Men. Cambridge University Press, 1991.

MEJÍA LARA, Amiel Ernenek. "Estar na cultura": os Tupinambá de Olivença e o desafio de uma definição de indianidade no sul da Bahia. Dissertação de Mestrado em Antropologia Social. PPGAS, Universidade Estadual de Campinas, 2012.

OLIVEIRA, João Pacheco de. (org) A presença indígena no Nordeste: processos de territorialização, modos de reconhecimento e regimes de memória. Rio de Janeiro: Contra Capa, 2011.

PERRONE-MOISÉS, Beatriz. "Bons chefes, maus chefes, chefões: elementos da filosofia política ameríndia”. Revista de Antropologia, São Paulo, USP, v.54, $\mathrm{n}^{\circ} \mathrm{O} 2, \mathrm{pp} .857-883,2011$.

STRATHERN, Marilyn. O Gênero da Dádiva: problemas com as mulheres e problemas com a sociedade na Melanésia. André Villalobos (trad.) Campinas, SP: Editora da Unicamp, 2006.

SZTUTMAN, Renato. O Profeta e o principal - A ação política ameríndia e seus personagens. São Paulo: Ed. Universidade de São Paulo, Fapesp, 2012.

VIEGAS, Susana. Relatório Circunstanciado para Identificação e Delimitação da Terra Indígena Tupinambá de Olivença, FUNAI, 2009.

. Terra Calada: os Tupinambá na Mata Atlântica do Sul da Bahia. Rio de Janeiro: 7Letras, 2007.

VIERA, José Glébson. Amigos e competidores: política faccional e feitiçaria nos Potiguara da Paraíba. Tese de Doutorado, PPGAS/ USP, 2010. 